\title{
Sport and the European Union: Foreword
}

\section{David Allen}

Whilst academics have researched the relationship between sport and politics and sport and international relations for some time now, sport as a focus of interest to scholars of European integration is a more recent phenomenon. Research was most obviously stimulated by the far reaching consequences of the Bosman judgement (1995) that related to the free movement between two EU member states of a footballer out of contract with his club. Although Bosman was initially of interest to students of EU law, its wider impact on various aspects of sports governance soon attracted the attention of political scientists and, to a lesser extent, economists and sociologists. In 2001 the European Union Studies Association (EUSA) meeting in Madison (Wisconsin) included a panel on the EU and football which was, I think, the first time that the issue of sport was seriously considered at this biennial conference of the leading international academic organisation for the study of the EU. Sport has also featured at UACES annual conferences, with a round table in 2003 in Newcastle and a panel on professional sport at Zagreb (Croatia) in 2005. In 2007 the EUSA conference in Montreal included two very well attended panels (on EU sports law and on EU football governance) sponsored by Sport\&EU - the newly established Association for the Study of Sport and the European Union (www.sportandeu.com). In this special issue of the JCER there are contributions from two of the founding members of Sport\&EU.

This is a particularly appropriate moment for the publication of a special issue on the EU and Sport as it marks the culmination of a number of significant developments in the area. In July 2007 the European Commission adopted its White Paper on Sport which builds on the Independent Review of European Sports initiated by the 2005 UK Presidency of the EU and, in October 2007, the leaders of the European Union adopted the Reform Treaty which, like its rejected predecessor (the Constitutional Treaty), includes, for the first time, sport amongst the list of EU competences. This requires the EU to 'contribute to the promotion of sporting issues, whilst taking account of the specific nature of sport, its structures based on voluntary activity and its social and educational function'. The objectives for EU action laid out in the Reform Treaty relate to all the issues discussed in the articles in this special edition, namely the development of the European dimension in sport, the promotion of fairness and openness in sporting competition, cooperation between bodies responsible for sports and the protection of the physical and moral integrity of those participating in sport.

The growth in the academic interest in sport and the EU has also led to an encouraging qualitative development in the work that is being produced which is also reflected in the articles included in this special edition. Whilst it is the case that law and political science remain the dominant subject areas and, whilst football remains the dominant sport in EU related studies, the work produced is now much better integrated with mainstream EU studies (utilising concepts such as Europeanisation or multi-level governance) than it was in the early days when it was, perhaps, the interest in a particular sport rather than EU studies that predominated. It can only be a matter of time before the editors of one or two of the leading compilations focusing on EU policy-making studies (such as Policy-Making in the European Union edited by Helen Wallace, William Wallace and Mark Pollack or European Union; Power and Policy-Making edited by Jeremy Richardson) recognise that it would be appropriate to include an EU sports related case study in their next editions. 
In this special issue we present six peer reviewed articles and one commissioned commentary article. Two (Brand and Niemann and García) focus on football, one (OwenPugh) on basketball and three (Kustec-Lipicer, Vermeersch and Rincón) on sport more generally. Four of the pieces take a political science perspective, two draw specifically on an understanding of EU law and one presents a sociological view of sport. Two (Brand and Niemann and Kustec-Lipicer) focus on developments in specific EU member states and two (García and Kustec-Lipicer) seek to utilise the EU-related concept of multi-level governance. Brand and Niemann seek to use football case studies to develop an understudied aspect of europeanisation - the societal/transnational dimension sometimes referred to as 'crossloading' to distinguish it from the more familiar notions of 'uploading' and 'downloading'. García and Moorhouse and, to a lesser extent, Kustec-Lipicer and Owen-Pugh, seek to identify and analyse the actors that are increasingly engaged in, or emerge from, the relationship between the EU and sport, whilst Vermeersch and Rincón focus on the legal arguments associated with articulating the important and relevant notion of the 'sporting exemption' based on an attempt to distinguish between and thus separate out the 'economic' and 'sporting' aspects of sports governance issues at the EU level.

Our last contribution (Moorhouse) was specially commissioned and asks some searching and fundamental questions about the real structure of power in European football and about how academics approach this subject. Moorhouse's critique of the self ascribed roles played by both Deloitte and UEFA in the governance of European football and of the uncritical acceptance by academics of these roles demonstrates that a proper understanding of sport in the EU requires both a critical eye and input from economics and sociology as well as law and political science. It is an indication of the growing maturity of the subject area that a special issue on the EU and sport should conclude with a piece that is concerned with fundamental social science questions about power, authority and influence.

Finally a word of thanks to my co-editor of this special issue. Borja García has been the driving force behind this edition and, along with JCER editor Eamonn Butler, has borne the brunt of the editorial work. Borja García is one of the leading young researchers in this area, he is a founder member of Sport\&EU and the organiser of its inaugural workshop at Loughborough in 2006. His article in this special issue was subjected to the same peer review process as all the other contributions.

David Allen

Professor of European and International Politics Loughborough University, UK

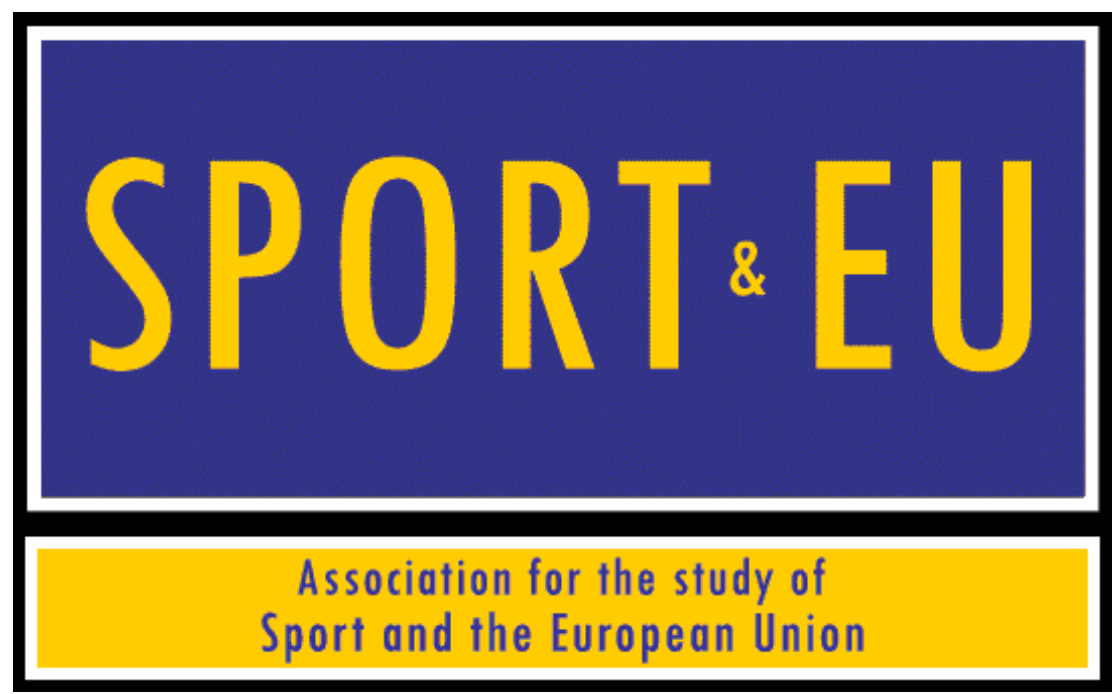

